\title{
Functional fitness: A key to independent and active living in the later age
}

\author{
Sonia Tewari*, Seema Kwatra and Neha Triphati \\ Department of Family Resource Management, College of Home Science, Govind Bhallabh Pant University of \\ Agriculture and Technology, Pantnagar, Pin code-263145, Udham Singh Nagar, (Uttarakhand), INDIA \\ *Corresponding author. E-mail: soniatewari38334@gmail.com
}

Received: July 8, 2015; Revised received: February 6, 2016; Accepted: May 4, 2016

\begin{abstract}
Aging is a biological process and is associated with decrease in the physical activity level. With the aim of assessing the functional fitness level of senior citizens, sample size comprised of 90 i.e. 45 males and 45 females (15 male and 15 female from each age group viz. 60-64 year 65-69 year and 70-74 year) were chosen conveniently from Haldwani Block of district Nainital, Uttarakhand, India. The Senior Fitness Test was conducted to collect experimental data. With age, lower body strength of males changes but not in case of females. The other functional parameters amongst males and females i.e. upper Body Strength, lower and Upper Body Flexibility, Aerobic Endurance and Balance does not depend on the age. Out of six parameters of functional fitness, it was found that the average mean score of lower body strength (5.96), upper body strength (3.52) and aerobic endurance (4.85) of males and females are highly significant at $1 \%$ level of significant while average upper body flexibility (2.52) of males and females were significant at $5 \%$ level of significance. With time, society has witnessed significant changes in lifestyle pattern, arising nuclear family groups, dual-earner families, competitiveness and rural-urban or cross-country immigration among young children. The scenario thus further placed need to lay emphasis on functional fitness of elderly population so that the older parents who are living alone can be functionally active and independent and care and rare themselves. Assessing the functional level of elderly can serve as a preventive measure prior to any functional limitations.
\end{abstract}

Keywords: Aerobic Endurance, Ageing, Flexibility, Functional Fitness, Strength

\section{INTRODUCTION}

Ageing is the biological process and is simply the maturation process that takes place since an individual's birth. But, old age term is being used to defined the elderly population of age 60 year or above and is associated with the sign and symptoms of decreased mobility, wrinkled skin, decreased physiological activity, weak immune system and decreased cognitive power. The other factors that are responsible for the poor condition of the elderly are their socio-economic status, poor nutrition, chronic illness, mental shock etc. Apart from these factors, the comfortable lifestyle as a result of raised living standards is also an important factor.

According to the Population Reference Bureau (2012) India's population ages 60 and older is projected to increase dramatically over the next four decades, The share of India's population ages 60 and older is from 8 percent in 2010 to 19 percent in 2050, according to the UNDP (2011). By mid-century, this age group is expected to encompass 323 million people, a number greater than the total U.S. population in 2012. This profound shift in the share of older Indians taking place in the context of changing family relationships and severely lim-ited old-age income support brings with it a variety of social, economic, and health care policy challenges. Balamurugan and Ramathirtham (2012) India is passing through technological, social, cultural and demographic transition. Consequently increase in awareness of health care among the people took place, which led to the improvement in the quality of health care facility. Eventually the mortality rate has come down due to an increase in the life expectancy, which ultimately leads to the increase in elderly population. Along with the growing number of the aged, the traditional family support system is fast disappearing from the Indian society.

Unfortunately higher age often brings about health problems and a decrease in functional capacity. This means that a growing number of people living with chronic diseases, health problems and decreasing capacity. In this twenty first centaury with advancement in technology, an individual dependent more on various gadgets and machines. These machines makes the life more comfortable by decreasing the physical activity participation and limits the movements in an individual, and hence responsible for the functional limitations. So, there is a need to determine Functional fitness of the senior citizens i.e. the physical capacity of an individual that is needed to undertake normal everyday activities, independently and without the early onset of fatigue. 


\section{MATERIALS AND METHODS}

Purposive sampling was adopted to select the study area and convenient sampling was adopted to select the sample in the study. For Senior Fitness Test a total sample size of 90 (45 males and 45 females) was taken, 15 males and 15 females from each age group i.e. 60-64 year, 65-69 year and 70-74 year. The criteria for selecting participants were: age between 60 and 74 years; physically independent person, i.e., able to walk 20 feet without assistance or rest; and lack of cognitive impairment and dementia.

The Physical Fitness of the respondents was assessed through Senior Fitness Test (SFT) developed by Rikli and Jones (2002) which includes test for lower and upper strength, test for lower and upper body flexibility, test for agility and test for aerobic endurance. The test protocols suggested by Rikli and Jones (2002) were adhered to, while going through testing procedure. The SFT includes the following:

Chair stand test: It is the 30 second test to determine the lower strength of the body in which number of full stands in 30 seconds with arms folded across chest is recorded.

Arm curl: Number of bicep curls in 30 seconds holding hand weight (women $5 \mathrm{lbs}, 2.27 \mathrm{~kg}$; men $8 \mathrm{lbs}, 3.63$ $\mathrm{kg}$ ) and helps to determine the upper body strength

Chair sit and reach test: From a sitting position at front of chair, with leg extended and hands reaching toward toes, the number of inches $(\mathrm{cm})(+$ or -$)$ between extended fingers and tip of toe. It is the test for lower body flexibility.

Back stretch test: With one hand reaching over the shoulder and one up the middle of the back, the number of inches $(\mathrm{cm})$ between extended middle fingers $(+$ or -). This is the test to check upper body flexibility.

Eight feet up and go test (agility/dynamic balance): Number of seconds to get up from a seated position, walk 8 feet $(2.44 \mathrm{~m})$, turn, and return to seated position.

Two Minute on steps in place test: Number of full steps in 2 minutes, raising each knee to a point midway between the patella (kneecap) and iliac crest (top hip bone). It is the test to assess aerobic endurance.

Every test has a different recommended score for men and women to decide the category of Functional Fitness Level i.e. below average, average and above average.

Statistical analysis: The $\mathrm{z}$ test was used to compare the average scores of functional fitness parameters of males and females while the Chi-square test for independent attributes was applied to find out relationship between functional fitness parameter with age groups of males and females (Agarwal,2005).

\section{RESULTS AND DISCUSSION}

Upper Body strength was determined by the arm curl test and it was found that in age group 60-64 year it was found that 60 percent of the males and approximately
47 percent of females were having average upper body strength. In age group 65-69 year, approximately 47 percent of male as well as female were having upper body strength above average and average respectively while in age group 70-74 year, 53.33 percent of males and 73.33 percent of females were having average upper body strength (Table 1).

Lower Body Strength of 66.66 percent of males and 40 percent of females was found to be average in age group 60-64; in age group 65-69 year it was found that 53.33 percent of male and 46.66 percent of the female were having average lower body strength; in age group 70-74 year it was found that 53.33 percent of male and 66.66 percent of the female were having average lower body strength (Table 1).

Upper Body flexibility was determined by back stretch test and it was found that 73.33 percent of the males of age group 60-64 year were having average upper body flexibility while in same age group 60 percent of the females were having upper body flexibility below the average level; approximately 74 percent males and eight percent females o of age group 65 -69 year were having average upper flexibility while in age group 70 -74 year 80 percent males and 60 percent females were having average upper body flexibility as per recommended ranges for test based on different groups (Table 1).

Through Chair sit and reach it was found that the lower body flexibility of approximately 87 percent of both males and females were having average lower body flexibility; while in the age group 65-69 year and 7074 year, 66.66 percent and 73.33 percent males were having average lower body flexibility while for females in the age group 65-69 year and 70 -74 year, 60 percent and 73.33 percent females were having average lower body flexibility respectively as per recommended ranges for test based on different groups (Table 1).

Aerobic endurance was found to be better in men than in female of all the age groups. More than 65 percent of men were lie in above average category among all age groups while less than 40 percent of female were having above average aerobic capacity among all age groups. In 8 feet up and go test approximately 87 percent of males and 60 percent of females of age group 60-64 year was found to have poor balance and lie in the category of below average; 60 percent and 73.33 percent of the males of age group 65-69 year and 70-74 year respectively were also having poor balance and agility while for females 73.33 percent and 93.33 percent in age group 65-69 year and 70-74 year respectively were also having poor balance and agility as per recommended ranges for test based on different groups (Table 1).

Comparing the average functional fitness parameters among males and female: For comparing the average scores of functional fitness parameters of males and females $\mathrm{z}$ test was applied. It was found that the average lower body strength (5.96), upper body 
Table 1. Frequency and percentage functional fitness level distribution of elderly of different age groups on the basic of recommended level of the different test.

\begin{tabular}{|c|c|c|c|c|c|c|c|c|}
\hline \multirow[b]{2}{*}{ S. N. } & \multirow{2}{*}{ Test } & \multirow{2}{*}{$\begin{array}{l}\text { Age } \\
\text { group } \\
\text { (Year) }\end{array}$} & \multicolumn{3}{|l|}{ Male } & \multicolumn{3}{|l|}{ Female } \\
\hline & & & $\begin{array}{l}\text { Below } \\
\text { average }\end{array}$ & Average & $\begin{array}{l}\text { Above } \\
\text { average }\end{array}$ & $\begin{array}{l}\text { Below } \\
\text { average }\end{array}$ & average & $\begin{array}{l}\text { Above } \\
\text { average }\end{array}$ \\
\hline \multirow{3}{*}{1.} & \multirow{3}{*}{$\begin{array}{l}\text { Arm curl test } \\
\text { (Upper Strength) }\end{array}$} & $60-64$ & $2(13.33)$ & $9(60)$ & $4(26.66)$ & $4(26.66)$ & $7(46.66)$ & $4(26.66)$ \\
\hline & & $65-69$ & $2(13.33)$ & $6(40)$ & $7(46.66)$ & $3(20)$ & $7(46.66)$ & $5(33.33)$ \\
\hline & & $70-74$ & $5(33.33)$ & $8(53.33)$ & $2(13.33)$ & $1(6.66)$ & $11(73.33)$ & $3(20)$ \\
\hline \multirow{3}{*}{2.} & Chair sit and Stand & $60-64$ & $4(26.66)$ & $10(66.66)$ & $1(6.66)$ & $9(60)$ & $6(40)$ & - \\
\hline & Test (Lower & $65-69$ & $1(6.66)$ & $8(53.33)$ & $6(40)$ & $8(53.33)$ & $7(46.66)$ & - \\
\hline & Strength) & $70-74$ & $6(40)$ & $8(53.33)$ & $1(6.66)$ & $4(26.66)$ & $10(66.66)$ & $1(6.66)$ \\
\hline \multirow{3}{*}{3.} & \multirow{3}{*}{$\begin{array}{l}\text { Back stretch Test } \\
\text { (upper Flexibility) }\end{array}$} & $60-64$ & $1(6.66)$ & $11(73.33)$ & $3(20)$ & $9(60)$ & $5(33.33)$ & $1(6.66)$ \\
\hline & & $65-69$ & 0 & $13(86.66)$ & $2(13.33)$ & $12(80)$ & $2(13.33)$ & $1(6.66)$ \\
\hline & & $70-74$ & $1(6.66)$ & $12(80)$ & $2(13.33)$ & $9(60)$ & $4(26.66)$ & $2(13.33)$ \\
\hline \multirow{3}{*}{4.} & \multirow{3}{*}{$\begin{array}{l}\text { Chair Sit and Reach } \\
\text { test (Lower Flexi- } \\
\text { bility) }\end{array}$} & $60-64$ & - & $13(86.66)$ & $2(13.33)$ & $2(13.33)$ & $13(86.66)$ & - \\
\hline & & $65-69$ & $3(20)$ & $10(66.66)$ & $2(13.33)$ & $5(33.33)$ & $9(60)$ & $1(6.66)$ \\
\hline & & $70-74$ & $1(6.66)$ & $12(80)$ & $2(13.33)$ & $4(26.66)$ & $11(73.33)$ & - \\
\hline \multirow{3}{*}{5.} & \multirow{4}{*}{$\begin{array}{l}2 \text { min step in place } \\
\text { (Aerobic endur- } \\
\text { ance) }\end{array}$} & $60-64$ & $1(6.66)$ & $3(20)$ & $11(73.33)$ & $5(33.33)$ & $4(26.66)$ & $6(40)$ \\
\hline & & $65-69$ & $1(6.66)$ & $4(26.66)$ & $10(66.66)$ & $4(26.66)$ & 7 (46.66) & $4(26.66)$ \\
\hline & & $70-74$ & $1(6.66)$ & $4(26.66)$ & $10(66.66)$ & $1(6.66)$ & $9(60)$ & $5(33.33)$ \\
\hline \multirow{3}{*}{6.} & & $60-64$ & $13(86.66)$ & $2(13.33)$ & _- & $9(60)$ & $6(40)$ & _- \\
\hline & \multirow[t]{2}{*}{$\begin{array}{l}8 \text { feet up and go } \\
\text { (Balance) }\end{array}$} & $65-69$ & $9(60)$ & $6(40)$ & - & $11(73.33)$ & $4(26.66)$ & - \\
\hline & & $70-74$ & $11(73.33)$ & $4(26.66)$ & & $14(93.33)$ & $1(6.66)$ & - \\
\hline
\end{tabular}

strength (3.52) and aerobic endurance (4.85) of males and females are highly significant at $1 \%$ level of significant while average upper body flexibility (2.52) of males and females were significant at $5 \%$ level of significance. Whereas there was no difference in the average of the lower body flexibility (0.53) and balance (1.82) of males and females (Table 2).

Relationship between functional fitness parameter with age groups of males and females: Relationship between functional fitness parameter with age groups of males and females can be find out the by applying Chi-square test for independent attributes, the functional Fitness parameters were classified as three levels i.e. below average, average, above average in order to find the dependency of functional fitness level and BMI on age group i.e. 60-64 year, 65-69 year and 70-74 year in males and females, Chi-square test of independence of two attributes was applied. The results of the chi square test revealed that functional fitness level of lower body strength in males differed with age as significant difference (chi-square score $=10.012$ ) was found among males of age group 60-64 years, 65-69 years and 70-74 years whereas in case of female no significant difference was found for the same parameter. However no relationship was established in lower and upper body strength, lower and upper body flexibility, aerobic endurance and balance in both males and females with age (Table 3). The differences between young and old elderly were due to the reduction of muscle strength.

In study on age-related decrease in physical activity and functional fitness among elderly men and women by Milanovic et al. (2013), it was found that significant differences $(\mathrm{P}<0.05)$ were found for all Senior Fitness tests (upper body flexibility, lower body flexibility, aerobic endurance, agility, Upper body strength and lower body strength) between young elderly (60-69 years) and old elderly (70-80) men. Similar results were found for the women, except no significant differences were found for the chair sit and reach and the 2-minute step test. So, the difference in lower body strength in males with age and the relationship of aerobic endurance and lower body flexibility in females were found to be similar with the study. While the results of some of the parameters contradicts with the study. For males parameters like upper body flexibility, lower body flexibility, aerobic endurance, agility, Upper body strength contradicts while in case of females the there was also no significant differences were found for upper body flexibility, , agility, upper body strength, lower body strength.

\section{Conclusion}

The conclusion of the present study was that the average mean score of lower body strength (5.96), upper body strength (3.52) and aerobic endurance (4.85) of males and females are highly and positively significant $(\mathrm{p}<0.01)$ while average upper body flexibility (2.52) of males and females were positively significant $(p<0.05)$ whereas no significant difference was found between males and females in terms of lower body flexibility and balance/agility. Also, significant difference (chi-square score $=10.012$ ) was found among males of age group 60-64 years, 65-69 years 
Table 2. $\mathrm{Z}$ values to compare the average functional fitness parameters among males and females.

\begin{tabular}{|c|c|c|c|c|c|c|}
\hline \multirow{2}{*}{ S. $\mathbf{N}$. } & \multirow{2}{*}{ Functional fitness parameters } & \multicolumn{2}{|c|}{ Male $(n=45)$} & \multicolumn{2}{|c|}{ Female $(n=45)$} & \multirow{2}{*}{$|\mathbf{Z}|$} \\
\hline & & Mean & SD & $\overline{\text { Mean }}$ & SD & \\
\hline 1. & $\begin{array}{l}30 \text { sec chair stand test for lower body strength } \\
\text { (in numbers) }\end{array}$ & 14.91 & 3.61 & 11 & 2.86 & $5.965^{* *}$ \\
\hline 2. & $\begin{array}{l}30 \mathrm{sec} \text { arm curl test for upper body strength } \\
\text { (in numbers) }\end{array}$ & 18.86 & 4.55 & 15.53 & 4.42 & $3.5215^{* *}$ \\
\hline 3. & Chair sit and reach test for lower body flexibility (inches) & -0.06 & 2.73 & -0.32 & 1.75 & 0.5379 \\
\hline 4. & Back starch test for upper body flexibility (inches) & 2.75 & 3.84 & 5.03 & 3.95 & $2.5273 *$ \\
\hline 5. & 8 feet up and go test for balance (in seconds) & 7.71 & 2.51 & 8.66 & 2.30 & 1.8719 \\
\hline 6. & $\begin{array}{l}2 \text { min step in place test for aerobic endurance } \\
\text { (in numbers) }\end{array}$ & 139.22 & 39.55 & 100.24 & 36.50 & $4.8586^{* *}$ \\
\hline
\end{tabular}

Note: *significant at $5 \%$ level of significance, ** significant at $1 \%$ level of significance

Table 3. Chi square values for finding relationship between level of functional fitness parameter with age groups of males and females.

\begin{tabular}{llll}
\hline Age group & Different functional fitness parameters or senior fitness test & $\begin{array}{l}\text { Male } \\
\text { Chi sq value }\end{array}$ & $\begin{array}{l}\text { Female } \\
\text { Chi sq value }\end{array}$ \\
\hline \multirow{2}{*}{$60-64 \mathrm{yr}$} & 30 sec chair stand test (lower body strength) & $10.012^{*}$ & 5.13 \\
$65-69 \mathrm{Yr}$ & 30 sec arm curl test (upper body strength) & 5.53 & 3.53 \\
$70-74 \mathrm{Yr}$ & Chair sit and reach test (lower body flexibility) & 3.9 & 2.11 \\
& Back starch test (upper body flexibility) & 2.11 & 2.37 \\
\hline
\end{tabular}

*significant difference; Chi square test was not applicable to 8 Feet up and Go test as there were no respondent in the Above Age category for both Male and Female. Chi square is also not applicable to BMI of men among different age groups as there was no respondent in under-weight category.

and 70-74 years in terms of functional fitness level of lower body strength whereas in case of female the same parameter noted no significant difference. The results thus obtained can majorly contribute to amendment of existing welfare policy framework for the elderly population.

\section{REFERENCES}

Agarwal, B.L. (2005). Basic statistics. $4^{\text {th }}$ ed. New Delhi. New Age International. 778p.

Balamurugan, J. and Ramathirtham, G. (2012). Health problems of aged people. International Journal of Research in Social Sciences, 2(3): pp 139-150.

Jones, C.J. and Rikli, R.E. (2002). Measuring functional fitness of older adults. The Journal on Active Aging. pp 24-30.
Milanovic, Z., Pantelić S., Trajković, N., Sporis, G., Kostic, R. and James, N. (2013). Age-related decrease in physical activity and functional fitness among elderly men and women. Medicine \& Science in Sports \& Exercise: DOI: $10.1249 / \mathrm{mss} .0 \mathrm{~b} 013 \mathrm{e} 31814844 \mathrm{~b} 7$

Population Reference Bureau (2012). India's aging population, pp 1-6. Retrieved on March, 122015 from www. prb.org/Publications/Reports/2012/india-olderpopulation.aspx.

Senior Fitness Test Kit. 'The Senior Fitness Test'. Retrieved on December, 152014 from www.topendsports.com/ testing/senior-fitness-test.htm

UNDP (2011). United Nations, Department of Economic and Social Affairs, Population Division (UNDP), World Population Prospects: The 2010 Revision, Volume I: Comprehensive Tables. ST/ESA/SER.A/313. 